\title{
Changing thyroid status related to pregnancy
}

\author{
P Shankar, A Kilvert, C Fox
}

\begin{abstract}
A case of post-thyroidectomy hypothyroidism is reported. The patient became euthyroid in three consecutive pregnancies, reverting to hypothyroid within three months of delivery on each occasion. The alteration in thyroid status is attributed to pregnancy related changes in antibody titres, though the laboratory data to confirm this are not available. (Postgrad Med F 2001;77:591-592)
\end{abstract}

Keywords: hypothyroidism; autoimmune thyroid disease; pregnancy

A 30 year old white woman presented to our endocrine clinic at 31 weeks' gestation in her first pregnancy in November 1995. In 1983 she had been treated by subtotal thyroidectomy for Graves' disease, after which she became hypothyroid and was treated with thyroxine 50 $\mu \mathrm{g}$ daily. During the second trimester her general practitioner noted a suppressed thyroid stimulating hormone (TSH), which persisted despite reduction of the thyroxine dose to $50 \mu \mathrm{g}$ on alternate days. When seen in the clinic she was asymptomatic and clinically euthyroid. Thyroid function tests five weeks after reducing the dose of thyroxine revealed a $\mathrm{TSH}$ concentration of $<0.05 \mathrm{mU} / 1$ (normal range 0.4-5.5) and total thyroxine $169 \mathrm{nmol} / \mathrm{l}$ (60-140). Blocking TSH receptor antibody (TSHRAb) titre, measured by radioreceptor assay using solubilised thyroid membranes, was raised at 43 (0-18). Thyroxine replacement was discontinued and she went on to have a normal delivery at term. Three months after delivery she became hypothyroid with $\mathrm{TSH} 10 \mathrm{mU} / 1$ and total thyroxine $48 \mathrm{nmol} / 1$. Thyroxine was recommenced.

In June 1997 she returned at 16 weeks into her second pregnancy. Thyroid function tests were again hyperthyroid with a TSH of $<0.05$ $\mathrm{mU} / 1$, total thyroxine $162 \mathrm{nmol} / \mathrm{l}$, and total triiodothyronine $2.8 \mathrm{nmol} / 1$ (0.9-2.8). Thyroxine was reduced from $75 \mu \mathrm{g}$ to $50 \mu \mathrm{g}$ daily. Eight weeks later she remained biochemically hyperthyroid and thyroxine was stopped. Thyroid function returned to the normal range within four weeks and she remained euthyroid until the end of the pregnancy. Blocking TSHRAb titre was 7 at 32 weeks. Thyroid function tests immediately after delivery showed a TSH of $2.2 \mathrm{mU} / 1$ and thyroxine 78 $\mathrm{nmol} / \mathrm{l}$, but three months postpartum she was hypothyroid with a TSH of $35.2 \mathrm{mU} / 1$. Thyroxine $75 \mu \mathrm{g}$ daily was restarted and thyroid function returned to normal.

\section{Learning points}

- Thyroid function should be closely monitored during pregnancy in women with pre-existing thyroid disorder.

- Hypothyroidism in Graves' disease after treatment is thought to be induced in two ways: autoimmune thyroid destruction and the predominant appearance of blocking TSH receptor antibody.

- Autoimmune thyroid disease is suppressed during pregnancy and is exacerbated in the postpartum period.

In September 1998 she was seen at 15 weeks into her third pregnancy. Thyroid function tests showed a TSH of $0.2 \mathrm{mU} / 1$, free thyroxine $13 \mathrm{pmol} / \mathrm{l}(10-18)$, and free triiodothyronine $4.2 \mathrm{pmol} / 1$ (3.4-5.4). The dose of thyroxine was reduced but TSH became fully suppressed and thyroxine was stopped at 27 weeks. TSHRAb (stimulatory and blocking) titres were negative. She remained euthyroid off treatment during the rest of the pregnancy and TSH was $2.3 \mathrm{mU} / 1$ six weeks postpartum. Three weeks postpartum blocking TSHRAb titre was 7. Fourteen weeks postpartum TSH was $12.2 \mathrm{mU} / 1$ with free thyroxine $9.3 \mathrm{pmol} / \mathrm{l}$, and free triiodothyronine $3.5 \mathrm{pmol} / \mathrm{l}$. Thyroxine was restarted and five months later thyroid function was in normal range on replacement.

\section{Discussion}

Pregnancy affects almost all aspects of thyroid hormone metabolism. Oestrogen stimulated increase in serum thyroxine binding globulin leads to a twofold rise in serum total thyroxine and triiodothyronine levels. Chorionic gonadotrophin (hCG) stimulates thyroxine and triiodothyronine production from the thyroid gland leading to a slight rise in free thyroxine and free triiodothyronine levels with a reciprocal decrease in serum TSH concentration. These values return to normal by 20 weeks of gestation and remain so until delivery. A rise in the glomerular filtration rate in pregnancy leads to increased renal clearance of iodide with consequent increase in dietary iodine requirement. ${ }^{1}$ Patients who are hypothyroid often require an additional $20 \%-30 \%$ of thyroxine over the non-pregnant thyroxine requirement ${ }^{2}$. Recent work by Haddow et al shows the effect of maternal hypothyroidism on the subsequent IQ of their children. ${ }^{3}$

Hyperthyroidism may be difficult to diagnose in early pregnancy, particularly in the 
presence of hyperemesis gravidarum, which may cause suppression of TSH and a rise in serum thyroxine and triiodothyronine as a result of hCG stimulation. ${ }^{1}$ However, the TSH concentration should return to normal by 14 weeks. Both Graves' disease and Hashimoto's thyroiditis may improve during pregnancy and are often exacerbated after parturition. ${ }^{4} \mathrm{Al}-$ though titres of TSHRAb decrease during pregnancy, they may not correlate well with the clinical state of the patient.

Our patient presented with Graves' disease and thus had autoimmune thyroid disease presumably with stimulatory TSHRAb, though these were not measured. The reversal of her post-thyroidectomy hypothyroid state during pregnancy suggests that the thyroid was partly suppressed by antibodies rather than simply caused by an inadequate thyroid remnant left after surgery. This points to the well documented, though unusual, phenomenon of stimulating antibodies converting to blocking antibodies after thyroid surgery. ${ }^{5}{ }^{6}$ It appears that this process was subsequently modified by pregnancy such that on three successive occasions, despite the increase in demands on the thyroid, she became hyperthyroid on replacement and thyroid replacement had to be stopped in order to keep her euthyroid. Measurements of blocking TSHRAb during second trimester in each pregnancy and postpartum were unhelpful being raised, undetectable, or normal on different occasions.

In summary this patient strikingly illustrates the change in thyroid function that may occur during pregnancy and we postulate that this results from a change in antibody titre.

1 Fantz CR, Dagogo-Jack S, Landenson JH, et al. Thyroid Fantz CR, Dagogo-Jack S, Landenson JH, et al. Thyroin Chem 1999;45:2250-8.

2 Schlienger JL, Dreyfus M. Grossesse et thyroide. F Gynecol Schlienger JL, Dreyfus M. Grossesse et
Obstet Biol Reprod (Paris) 1993;22:521-7.

3 Haddow JE, Palomaki GE, Allan WC, et al. Maternal thyroid deficiency during pregnancy and subsequent neuropsychological development of the child. N Engl F Med 1999; 341:549-55.

4 Davies TF. The thyroid immunology of the postpartum period. Thyroid 1999;9:675-84.

5 Larsen PR, Davies TF, Hay ID. The thyroid gland. In: Wilson JD, Foster DW, Kronenberg HM, et al, eds. Williams textbook of endocrinology. 9th Ed. Philadelphia: W B Saunders, 1998:389-515.

6 Amino N. Autoimmunity and hypothyroidism. Baillieres Clin Endocrinol Metab 1998;2:591-617.

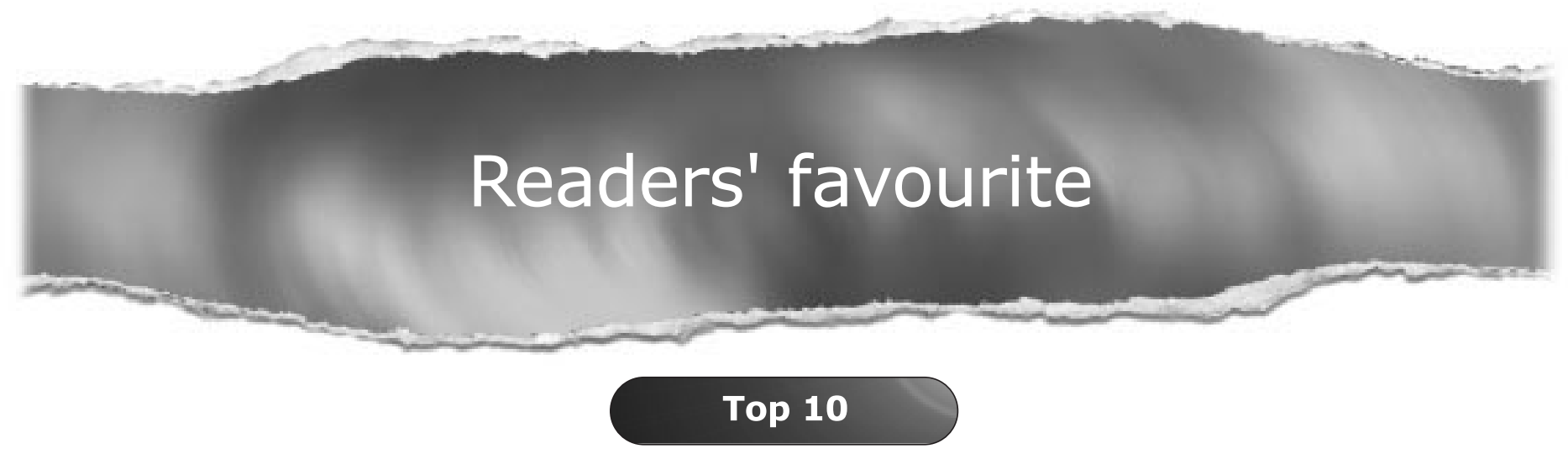

Click on the "Top 10" button on the homepage to see which are the best read articles each month

www.postgradmedj.com 